\title{
Total cavopulmonary conversion and maze procedure for patients with failure of the Fontan operation
}

Constantine Mavroudis, MD

Carl L. Backer, MD

Barbara J. Deal, MD

Christopher Johnsrude, MD

Janette Strasburger, MD

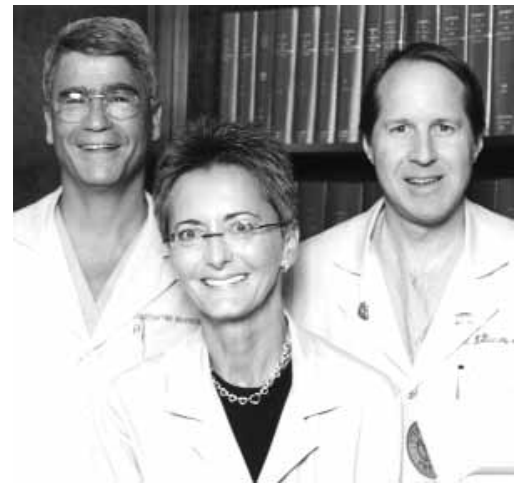

Drs Mavroudis, Deal, and Backer (left to right)
Objectives: Hemodynamic abnormalities and refractory atrial arrhythmias in patients late after the Fontan operation result in significant morbidity and mortality. We review our experience with conversion to total cavopulmonary artery connections and arrhythmia surgery.

Methods: Between 1994 and 2001, 40 patients underwent Fontan conversion and arrhythmia surgery. Significant hemodynamic lesions such as aortic aneurysm $(\mathrm{n}=$ $1)$, atrioventricular valve insufficiency $(n=8)$, and pulmonary arterioplasty $(n=9)$ were repaired concomitantly. Thirty-four patients were in New York Heart Association class III or IV. Mean age at the original Fontan operation was 7.5 \pm 6.5 years and mean age at Fontan conversion was $18.7 \pm 9.0$ years. Arrhythmia surgery has evolved from isthmus cryoablation in 10 patients to right-sided maze in 16 patients for atrial reentry tachycardia. The maze-Cox III operation was used for 14 patients with atrial fibrillation. Atrial $(n=33)$ and dual-chamber $(n=5)$ pacemakers were placed.

Results: There has been no early mortality. Chest tubes were removed on postoperative day $9.0 \pm 6.0$. Hospital stay was $11.8 \pm 6.6$ days. Three patients required cardiac transplantation at 8 days, 9 months, and 33 months postoperatively. There was 1 death 2 years postoperatively from acute myocardial infarction. For the entire series, arrhythmia recurrence is $12.5 \%$, with only $10 \%$ of patients receiving longterm antiarrhythmic medications; these patients were among the first 8 patients in our series. Most patients are in New York Heart Association class I or II. Bruce protocol in 12 patients showed increased tolerance $(P<.05)$.

Conclusions: Fontan conversion to total cavopulmonary connection with concomitant arrhythmia surgery is excellent therapy for patients whose Fontan repair has failed. Fontan conversion is safe, improves New York Heart Association class, improves exercise tolerance, and has a low incidence of recurrent arrhythmias.

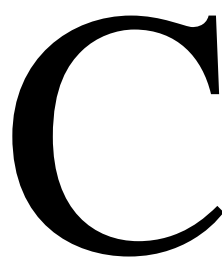

omplications after the Fontan operation are related to follow-up duration and include atrial arrhythmias, circulatory pathway obstructions, decreased ventricular function, increasing cyanosis, and protein-losing enteropathy, among others. ${ }^{1-4}$ Most of these complications occur in patients with atriopulmonary connections as opposed to the newer reconstructions in which total cavopulmonary artery connections (TCPC) with lateral tunnel or extracardiac techniques are used..$^{5-9}$ Whether this difference is due to the longer follow-up time of patients with atriopulmonary connections or the demonstrated improved flow characteristics of
From the Division of CardiovascularMedical School, Chicago, Ill.

Read at the Eighty-first Annual Meeting of Surgery, San Diego, Calif, May 6-9, 2001.

erved for publication April 4, 2001; revition June 5, 2001. Children's Plaza m/c 22 Chicago, IL 60614 (E-mail: c-mavroudis@northwestern.edu).

J Thorac Cardiovasc Surg 2001;122:863-71

Copyright (C) 2001 by The American Association for Thoracic Surgery

$0022-5223 / 2001 \$ 35.00+0 \quad \mathbf{1 2 / 6 / 1 1 7 8 4 0}$

doi: $10.1067 / \mathrm{mtc} .2001 .117840$ 
TABLE 1. Patient characteristics

\begin{tabular}{|c|c|c|c|c|c|}
\hline & & Isthmus block ( $n=10$ ) & Modified maze $(n=16)$ & Maze-Cox III (n= 14) & $P$ value \\
\hline \multirow[t]{6}{*}{ Diagnosis, $\mathrm{n}(\%)$} & $\mathrm{TA}$ & $6(60 \%)$ & $4(25 \%)$ & $11(78 \%)$ & \\
\hline & DILV & $1(10 \%)$ & $4(25 \%)$ & $1(7 \%)$ & \\
\hline & SV & $3(30 \%)$ & $2(12.5 \%)$ & 0 & \\
\hline & DORV, mitral atresia & 0 & $2(12.5 \%)$ & $2(14 \%)$ & \\
\hline & HLHS & 0 & $2(12.5 \%)$ & 0 & \\
\hline & Hypoplastic RV, PS & 0 & $2(12.5 \%)$ & 0 & \\
\hline Age at first Fontan (y) & & $6.1 \pm 3.0$ & $6.1 \pm 3.9$ & $9.9 \pm 9.4$ & NS \\
\hline Age at SVT onset (y) & & $11.7 \pm 5.7$ & $11.0 \pm 7.2$ & $15.1 \pm 8.4$ & NS \\
\hline \multirow[t]{3}{*}{ Catheterization results } & $\mathrm{RAp}(\mathrm{mm} \mathrm{Hg})$ & $16.2 \pm 3.2$ & $14.9 \pm 2.2$ & $14.3 \pm 2.9$ & NS \\
\hline & RVEDP or LVEDP $(\mathrm{mm} \mathrm{Hg})$ & $8.0 \pm 3.7$ & $7.6 \pm 2.0$ & $8.7 \pm 3.2$ & NS \\
\hline & $\mathrm{Cl}\left(\mathrm{L} \cdot \mathrm{min}^{-1} \cdot \mathrm{m}^{2}\right)$ & $2.3 \pm 0.7$ & $2.9 \pm 0.7$ & $2.3 \pm 0.6$ & NS \\
\hline $\begin{array}{l}\text { Age at CMH Fontan } \\
\text { conversion (y) }\end{array}$ & & $15.6 \pm 5.1$ & $16.2 \pm 7.7$ & $23.3 \pm 10.5$ & $P=.01$ \\
\hline $\begin{array}{l}\text { Interval: SVT onset to } \\
\text { CMH Fontan conversion }\end{array}$ & & $3.6 \pm 2.4$ & $5.9 \pm 3.8$ & $8.3 \pm 4.1$ & $P=.02$ \\
\hline \multirow[t]{2}{*}{ Intraoperative results } & CPB time (min) & $256 \pm 91.6$ & $205.2 \pm 86.2$ & $271 \pm 68.8$ & NS \\
\hline & Crossclamp time (min) & $21.4 \pm 32.1$ & $66.1 \pm 57.2$ & $97.5 \pm 25.6$ & $P=.003$ \\
\hline \multirow[t]{4}{*}{ Associated repairs } & PA plasty & 4 & 2 & 3 & \\
\hline & Valve repair & 0 & 5 & 1 & \\
\hline & Valve replacement & 0 & 1 & 1 & \\
\hline & Aortic root replacement & 0 & 0 & 1 & \\
\hline Postoperative complications & Renal failure (creatinine $>2.0$ ) & $0.8 \pm 0.2$ & $0.8 \pm 0.2$ & $2.1 \pm 1.8$ & $P=.001$ \\
\hline
\end{tabular}

$\mathrm{Cl}$, Cardiac index; $C M H$, Children's Memorial Hospital; $C P B$, cardiopulmonary bypass; DILV, double-inlet left ventricle; DORV, double-outlet right ventricle; $H L H S$, hypoplastic left heart syndrome; $L V E D P$, left ventricular end-diastolic pressure; $N S$, not significant; $P A$, pulmonary artery; $P A p$, mean pulmonary artery pressure; $P S$, pulmonary stenosis, $R V$, right ventricle; $R A p$, mean right atrial pressure; $R V E D P$, right ventricular end-diastolic pressure; $S V$, single ventricle; $S V T$, supraventricular tachycardia; $T A$, tricuspid atresia. Because isthmus block and the modified right-sided maze procedure are right atrial procedures, the results were combined and then compared with the more extensive right- and left-sided maze-Cox III procedure by the Student $t$ test. This comparison emphasizes the significant differences between operations that are performed for atrial reentry tachycardia and atrial fibrillation.

$\mathrm{TCPC}^{10,11}$ and decreased suture $\operatorname{load}^{12}$ remains to be reviewed as the TCPC group accrues longer follow-up time.

Whatever the eventual outcome of the TCPC Fontan procedure, the extant group of patients who had the atriopulmonary Fontan operation is presenting with an increasing incidence of complications that are often amenable to reconstructive and arrhythmia ablative techniques. Our previous reports on this subject introduced the idea that atriopulmonary Fontan conversion to TCPC in association with arrhythmia ablative surgery could be safely performed with a high degree of efficacy and improved functional class. ${ }^{13-15}$ These results were in contrast with previous ${ }^{16-19}$ and subsequent ${ }^{20,21}$ reports in which Fontan conversion was performed without arrhythmia surgery, resulting in excellent hemodynamic results but a collective $76 \%$ postoperative arrhythmia recurrence. Since our previous report, ${ }^{13}$ our arrhythmia ablative techniques have evolved into standard right-sided and left-sided procedures to treat atrial reentry tachycardia and atrial fibrillation, respectively. The purpose of this article is to document the matured right- and left-sided arrhythmia ablative procedures and update the clinical results of our enlarged series of patients.

\section{Patients and Methods Patient Population}

Between 1994 and 2001, 40 patients underwent Fontan conversion and arrhythmia surgery. The clinical characteristics of our patient population are noted in Table 1. Hemodynamic abnormalities were present in 38 of 40 patients; the New York Heart Association classification was class II in 4 patients, class II-III in 2 patients, class III in 28 patients, class III-IV in 1 patient, and class IV in 5 patients. Thirty patients had a severely dilated right atrium; 8 had elevated ventricular end-diastolic pressure $(\geq 12 \mathrm{~mm} \mathrm{Hg}) ; 8$ had a right atriumpulmonary artery gradient greater than $2 \mathrm{~mm} \mathrm{Hg} ; 5$ had pulmonary vein obstruction; 7 had right-to-left shunting; and 1 had significant pulmonary arteriovenous fistulas resulting from preexisting right Glenn-right atrial-left pulmonary connections. No patient in this series had significant protein-losing enteropathy. In 12 of 16 patients completing a standard Bruce treadmill protocol, both preoperative and postoperative evaluation were completed and results were compared by the Student $t$ test.

During this time period, 11 patients were evaluated for cardiac transplantation. Six of these underwent Fontan conversion because the ventricular dysfunction could be ascribed to arrhythmogenic or anatomic substrates, with a chance that the ventricular function would improve if these problems could be successfully addressed. 


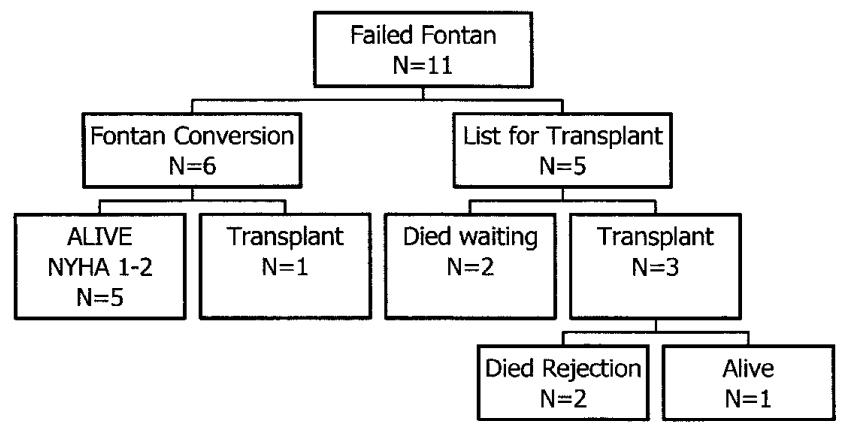

Figure 1. Road map figure noting the outcome of the 11 patients with failed Fontan operations who were initially considered for cardiac transplantation. Six patients, who are included in our cohort of 40 patients, had Fontan conversion with arrhythmia surgery. Five are alive and well $1.1 \pm 0.5$ years postoperatively and 1 had a subsequent cardiac transplant and is alive and well 1.8 years after transplantation. Five, not included in our original cohort of $\mathbf{4 0}$ patients, were listed for cardiac transplantation. Two died on the waiting list and the other 3 had cardiac transplantation. Only 1 of these patients survives, 1.6 years postoperatively. The other 2 died 1 and 4.2 years after the transplant operation.

Another 5 patients, not included in our original cohort of 40 patients, had ventricular dysfunction that could not be ascribed to arrhythmogenic or anatomic substrates. These patients were listed for cardiac transplantation without consideration for Fontan conversion. The clinical outcome of all patients who were considered for cardiac transplantation is noted in Figure 1.

\section{Arrhythmia Management}

All patients with atrial reentry tachycardia underwent preoperative, intraoperative, and postoperative electrophysiologic study and mapping, the results of which are published elsewhere. ${ }^{14,15}$ Early in our series, isthmus block via cryoablation at the area between the coronary sinus os and the inferior vena cava os and the right-sided atrioventricular valve (when present) was performed. ${ }^{13}$ On the basis of the multiplicity of reentrant circuits identified at preoperative and intraoperative electrophysiologic assessment, the cryoablation procedure was extended to three main parts of the right atrium. ${ }^{13}$ Since that report, we have standardized intraoperative arrhythmia management by performing a modified right-sided maze procedure (Figures 2-4) for patients with atrial reentry tachycardia and a maze-Cox III operation (Figure 5) for patients with atrial fibrillation. ${ }^{22}$ Twenty-five patients had right-sided arrhythmia surgery and were treated for atrial reentry tachycardia; 8 with isthmus cryoablation and 15 with the standard modified right-sided maze procedure. Two patients without prior atrial tachycardia underwent prophylactic cryoablation, 1 with isthmus ablation and 1 with the modified right-sided maze procedure. Fifteen patients had arrhythmia surgery for atrial fibrillation, 14 with the standard maze-Cox III procedure and 1 with isthmus ablation. Interestingly, all patients who had atrial fibrillation also had a history of recurrent atrial reentry tachycardia, which underlines the linear propensity for arrhythmia degeneration.

Thirty-eight of 40 patients had a planned pacemaker implantation or replacement $(n=3)$ at the time of Fontan conversion consistent with our original protocol ${ }^{13}$ for management of sinus node dysfunction. In
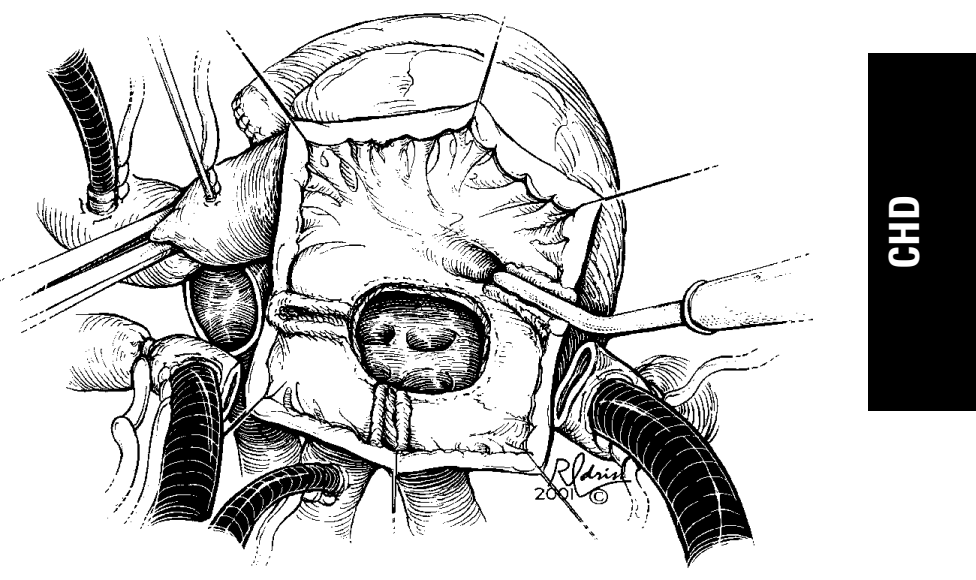

Figure 2. Atrial view of a patient who had an atriopulmonary Fontan operation after aortic crossclamping and cardioplegic arrest. The inferior and superior venae cavae have been transected, the atrial wall excision has been performed, and the atrial septal patch has been removed. No measures are taken to preserve the sinoatrial node, which is nonfunctional in a significant number of patients. Cryoablation lesions $\left(-60^{\circ} \mathrm{C}\right.$ for 90 seconds) are placed in 3 areas to complete the modified right-sided maze procedure. The first 2 cryoablation lesions are standard for all anatomic substrates and are performed by connecting (1) the superior portion of the atrial septal ridge with the incised area of the right atrial appendage and (2) the posterior portion of the atrial septal ridge with the posterior cut edge of the atrial wall, which extends through the crista terminalis. The third part is the isthmus ablation. These lines of block are dependent on the anatomic substrate. In patients with tricuspid atresia, as noted here, the cryoablation lesion is placed to connect (3) the posteroinferior portion of the coronary sinus os with the transected inferior vena cava os.

our early experience, we implanted antitachycardia pacemakers in the event of arrhythmia ablation failure. Because the Intermedics Intertach II (Intermedics, Inc, Angleton, Tex) antitachycardia pacemaker was withheld from the market, we converted to atrial rate-responsive pacemakers (Medtronic, Inc, Minneapolis, Minn; Thera DR). The rationales for pacemaker implantation are the high incidence of sinus node dysfunction in these patients, the desirability of rate-responsive paced sinus rhythm, and the lack of venous access to the heart in these patients, which would require mandatory thoracotomy for subsequent pacemaker implantation. Our bias is to maintain a regular paced atrial rhythm to prevent bradycardia and to decrease atrial extrasystoles, which are substrates for atrial reentry tachycardia. Seven had an atrial antitachycardia pacemaker (not currently available), 26 had an atrial rate-responsive pacemaker, and 5 had a dual-chamber pacemaker. Perioperative prophylactic arrhythmia management has evolved over the course of the study. Unless contraindicated by noncardiac problems, after surgery we administer oral $\beta$-blockade for 3 months to patients who had atrial reentry tachycardia and oral amiodarone for 3 months to those who had atrial fibrillation.

\section{Anatomic Conversion}

The preoperative Fontan reconstructions were mostly atriopulmonary connections $(\mathrm{n}=31)$, of which 8 had divided circulations consisting 


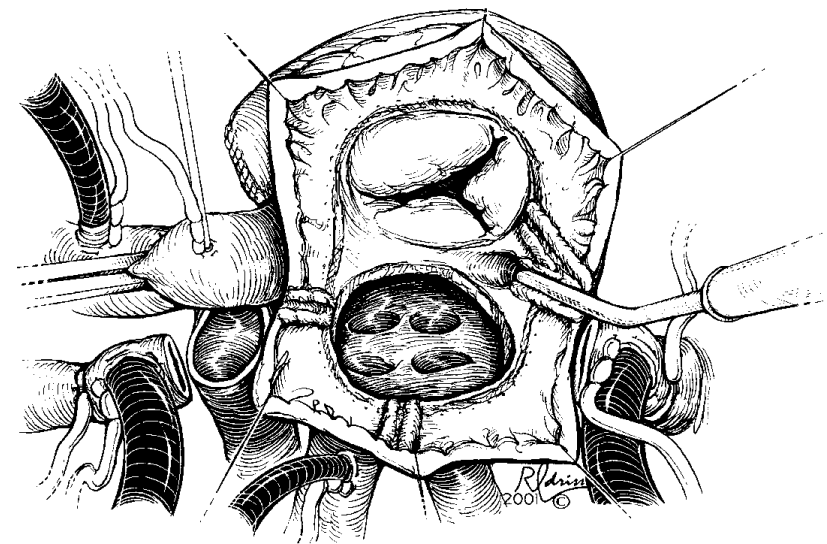

Figure 3. This drawing demonstrates the modified right-sided maze procedure in a patient with double-outlet right ventricle and mitral atresia. As noted in Figure 2, the 2 standard cryoablation lesions connecting the rim of the atrial septal defect with (1) the incised area of the right atrial appendage and (2) the posterior cut edge of the atrial wall, respectively, are shown. The isthmus block is accomplished by creating cryoablation lesions (3) to connect the posteroinferior portion of the coronary sinus os with the transected inferior vena cava os, and (4) to connect the tricuspid valve anulus with the transected inferior vena cava os. These isthmus block lesions are usually placed across the ridge of the resected atrial compartmentalization patch.

of right Glenn-right atrium-left pulmonary artery anastomoses. Six patients had Björk modifications (right atrium-small right ventricle connections); 2 had total cavopulmonary artery lateral tunnel connections; and 1 had an intra-atrial graft reconstruction for heterotaxy syndrome. Thirty-eight of 40 patients had TCPC, of whom 32 had extracardiac and 6 had lateral tunnel inferior vena cavapulmonary artery connections. In 7 of the 8 patients with a divided pulmonary circulation, the circulation was reconnected by homograft or polytetrafluoroethylene* tube grafts. A liberal right atrial wall resection was performed without regard to preservation of the sinoatrial node, because all patients receive an atrial or dual-chamber pacemaker. Only 1 patient in the entire series had a fenestration, which was associated with a lateral tunnel reconstruction. In 1 early patient the right atrial-left pulmonary artery connection was revised, and in the other patient the Fontan circulation was converted to a one and a half ventricle repair because of the interim growth of the right ventricle. ${ }^{23}$ The mean/median ages at the initial Fontan operation were $7.5 \pm 6.5$ years and 5.7 years, respectively. The mean/median ages at the latest Fontan conversion were $18.7 \pm$ 9.0 years and 16.5 years, respectively. Associated surgical procedures were performed as required by the anatomic substrates. The procedures included atrioventricular valve repair/replacement in 8 patients, pulmonary artery arterioplasty in 9 patients, and aortic root

*Gore-Tex graft; registered trade name of W. L. Gore \& Associates, Inc, Flagstaff, Ariz.

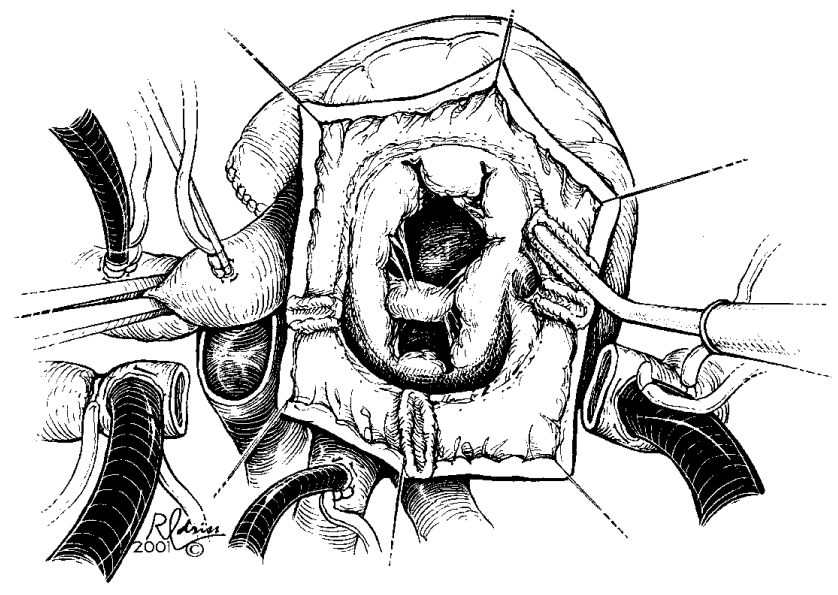

Figure 4. This drawing demonstrates the modified right-sided maze procedure in a patient with single ventricle and unbalanced atrioventricular canal. As noted in Figure 2, the 2 standard cryoablation lesions connecting the rim of the atrial septal defect with (1) the incised area of the right atrial appendage and (2) the posterior cut edge of the atrial wall, respectively, are shown. The isthmus block is accomplished by creating cryoablation lesions (3) to connect the posteroinferior portion of the coronary sinus os with the transected inferior vena cava os and (4) to connect the common atrioventricular valve anulus with the transected inferior vena cava os. These isthmus block lesions are usually placed across the ridge of the resected atrial compartmentalization patch.

replacement in 1 patient. Femoral cannulation during or before median resternotomy was required for excessive bleeding, unwanted cavitary entry, or dissection enhancement in 5 patients.

\section{Follow-up Monitoring}

All patients received follow-up on at least a yearly basis with physical examination, echocardiogram, electrocardiogram, continuous 24-hour electrocardiographic monitoring, and pacemaker analysis. Exercise testing was obtained in 16 patients postoperatively, with both preoperative and postoperative assessment in 12 of 16 . Although these 12 patients had combinations of pathway obstruction and atrial tachycardia, the primary indication for Fontan conversion and arrhythmia surgery was atrial reentry tachycardia in 7, pathway obstruction in 4, and circular venous circulation caused by right atrial-main pulmonary artery connection and TCPC in 1 . None of these 12 patients had preexisting valve lesions. The average follow-up time was $2.5 \pm 1.9$ years (range 1 month-6.3 years) and was complete. All patients were given warfarin sodium (Coumadin; international normalized ratio, 2-2.5); none has been converted to antiplatelet therapy.

\section{Statistical Analysis}

Means are expressed as \pm standard deviation; comparison of groups with normal distribution was analyzed by the Student $t$ test. Because isthmus block and the modified right-sided maze procedure are right atrial procedures, the results were combined and then compared with the more extensive right- and left-sided maze-Cox III procedure by the Student $t$ test. This comparison emphasizes the significant differ- 


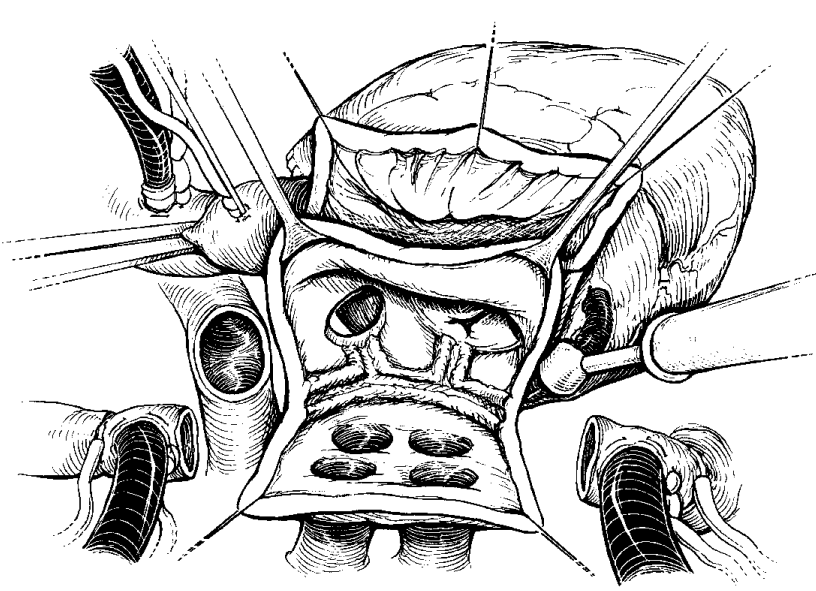

Figure 5. Left atrial view of a univentricular heart that shows the standard incisions, excisions, and cryoablation lesions which, when combined with the right atrial component (see Figures 2-4), complete the maze-Cox III procedure. The incisions include a partial encircling pulmonary vein isolation and a left atrial appendage resection. Standard cryoablation lesions $\left(-60^{\circ} \mathrm{C}\right.$ for 90 seconds) are placed to complete the pulmonary vein isolation, to create a cryoablation lesion from the isolated pulmonary veins toward the posterior mitral or tricuspid valve anulus, and to extend the pulmonary vein isolation to the cut edge of left atrial appendage base. A large cryoablation probe $(15 \mathrm{~mm})$ is used to place a lesion on the coronary sinus $\left(-60^{\circ} \mathrm{C}\right.$ for 180 seconds). (Copyright (C) 2001 R. F. Idriss.)

ences between operations that are performed for atrial reentry tachycardia and atrial fibrillation.

\section{Results}

\section{Operative Outcomes}

All patients survived the operation ( $0 \%$ mortality). No patient required reexploration for bleeding. The average hospital stay was $11.8 \pm 6.8$ days (range 7-36 days, median 10 days). Chest tube output was favorable in most cases (removal of the last chest tube on postoperative day $9.0 \pm 6.0$ days, range 5-36 days, median 7.5 days).

\section{Complications}

One 47-year-old man with tricuspid atresia had his initial Fontan operation at 35 years of age and presented with an elevated left ventricular end-diastolic pressure $(13 \mathrm{~mm} \mathrm{Hg}$ ) and atrial fibrillation. Acute renal failure developed postoperatively, resulting in fluid retention, recurrence of atrial fibrillation, and cardiac decompensation 7 days postoperatively. $\mathrm{He}$ was supported with a ventricular assist device and required expeditious cardiac transplantation 16 hours later. He is doing well 17 months postoperatively and is awaiting renal transplantation. One 40-year-old woman with an associated ascending aortic aneurysm repair had a deep mediastinal infection, which was successfully treated by debridement and

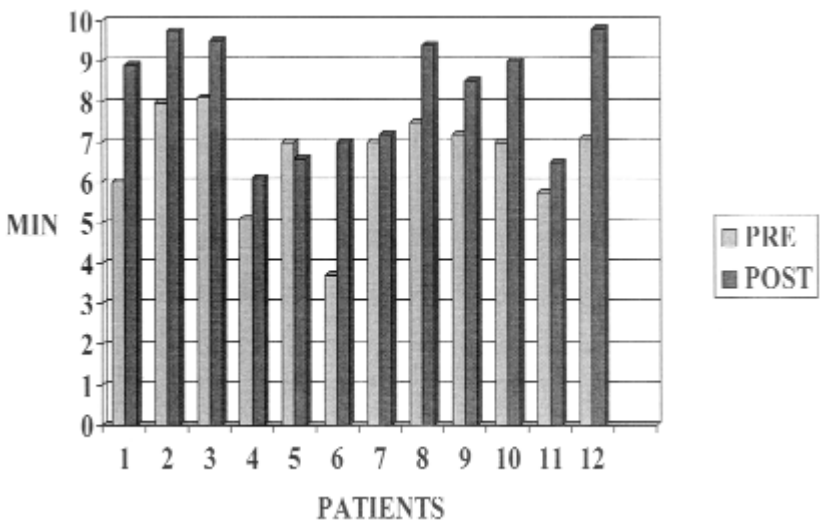

Figure 6. Bar graph showing the results of exercise tolerance (Bruce protocol) before and after Fontan conversion and arrhythmia surgery $(P<.05$; Student $t$ test $)$.

myocutaneous flaps at another institution without long-term sequelae. Five patients in the maze-Cox III group had acute renal failure manifested by oliguria and a perioperative rise in the serum creatinine measurement (peak postoperative creatinine level $4.8 \pm 1.1 \mathrm{mg} / \mathrm{dL}$ ), presumably because of susceptibility to renal insufficiency from long-standing heart failure, prolonged cardiopulmonary bypass time, excessive cardiotomy suction, and resultant hemoglobinuria. All responded to conservative measures except the cardiac transplant patient, as noted above. Oxygen saturations improved postoperatively from $72 \%$ to $93 \%$ within 4 months and to $98 \%$ at 14 months' follow-up in the 1 patient who had significant pulmonary arteriovenous fistulas.

\section{Arrhythmia Status}

Two patients had transient perioperative heart block, which resolved. Overall recurrence of tachycardia is 5 of 40 patients $(12.5 \%)$ with a mean follow-up of $30.0 \pm 22.6$ months. Among 23 patients with atrial reentry tachycardia, isthmus cryoablation was performed in 8 and a modified right atrial maze procedure in 15 patients. Atrial tachycardia recurred late postoperatively in 4 of 8 patients undergoing isthmus cryoablation and in none of those undergoing a modified right atrial maze procedure $(P<.05)$. $\beta$-Blocking medications were effective in 3 patients, and 1 patient is receiving no medications, treated with the antitachycardia pacemaker with 66 months' follow-up. Among 15 patients with atrial fibrillation, isthmus cryoablation was performed in 1 patient, who is receiving amiodarone therapy for chronic atrial fibrillation 51 months postoperatively. Of 14 patients undergoing the maze-Cox III procedure for atrial fibrillation, 4 (29\%) had acute perioperative supraventricular tachycardia, and 1 patient underwent heart transplantation. During long-term follow-up of $19 \pm 18$ months, with discontinuation of antiarrhythmic medications 3 months postoperatively, none of 13 patients have had recurrence of supraventricular tachycardia. 
Two patients underwent prophylactic arrhythmia surgery: isthmus cryoablation in 1 and modified right atrial maze procedure in the other. Neither patient has had tachycardia during 40 months' follow-up.

\section{Late Follow-up}

There was 1 late death (3\%) 2 years postoperatively in a 26year-old man who had an acute myocardial infarction as a result of right coronary artery occlusive thrombosis and was found to have diffuse obstructive atherosclerotic coronary artery disease at autopsy. He had no positive family history, and his lipid profile was unknown. Two other patients with double-outlet right ventricle required cardiac transplantation 2.8 years and 9 months postoperatively because of decreasing ventricular function in both. No clinical thromboembolic or hemorrhagic events have been noted.

\section{Exercise Endurance}

Sixteen patients have undergone follow-up Bruce exercise tolerance testing at this institution from 1 to 4 years postoperatively. In 12 patients both preoperative and postoperative evaluations were performed. The results of the most recent evaluations demonstrate that exercise endurance improved significantly from $6.51 \pm 1.20$ minutes to $8.40 \pm 1.51 \mathrm{~min}-$ utes $(P<.05$, paired Student $t$ test). There was a significant improvement in New York Heart Association class $(P<$ .001 , Mann-Whitney rank sum test): class I, 12 patients; class I-II, 17 patients; class II, 5 patients; class III, 3 patients; and class IV, 3 patients (all patients with class IV cardiac function eventually required cardiac transplantation). This was corroborated by an increase in exercise tolerance (Bruce protocol) after Fontan conversion and arrhythmia surgery (Figure 6).

\section{Discussion}

Our findings demonstrate that atriopulmonary to total cavopulmonary Fontan conversion in association with arrhythmia surgery is a highly effective and safe operation, which results in near-uniform arrhythmia control, increased functional class, and increased exercise tolerance. Our selection criteria were liberal and included patients with severe ventricular dysfunction, cyanosis-causing pulmonary arteriovenous fistulas, and significant associated cardiac lesions. However, no patient had debilitating protein-losing enteropathy, which is a known risk factor for poor outcome. ${ }^{4}$ Eleven patients were evaluated for cardiac transplantation because of severe ventricular dysfunction (Figure 1). Six of those who eventually underwent Fontan conversion and arrhythmia surgery had anatomic and arrhythmogenic substrates amenable to surgery. The other 5 (not included in our original cohort of 40 patients) had severe ventricular dysfunction, which could not be ascribed to atrial arrhythmias or anatomic lesions; 3 of these patients had cardiac transplantation and the other 2 died while on the waiting list. Cardiac transplantation after Fontan conversion was performed in 3 of our patients from the original cohort, which is similar to the incidence reported in long-term follow-up studies. ${ }^{24}$

\section{Arrhythmia Surgery}

The operation that we first introduced in 1994 for patients with anatomic hemodynamic problems and debilitating arrhythmias after the Fontan operation has undergone a significant metamorphosis ${ }^{13,14,22}$ based on the analysis of our extensive electrophysiologic findings. ${ }^{15}$ We found an unacceptable arrhythmia recurrence after Fontan conversion with isthmus block alone (4/8 patients). Using extensive electrophysiologic mapping, we identified additional areas of atrial reentry for which simple isthmus block was not adequate. We have identified 3 common sites within the right atrium important to these reentrant circuits: (1) the area between the coronary sinus os and the inferior vena cava os/right-sided atrioventricular anulus, (2) the region of the atrial septal defect patch, and (3) the lateral right atrial wall. These areas of reentry became the target for our revised approach to atrial reentry tachycardia, which resulted in the modified right-sided maze procedure. ${ }^{22}$ We use the term "modified" to distinguish this arrhythmia operation from the "right-sided maze procedure" that was used by Theodoro and associates $^{25}$ in patients with congenital heart disease not amenable to the Fontan procedure.

\section{Anatomic Variants}

We found that the anatomic substrate had a profound effect on how we handled the cryoablation lesion at the isthmus (area between the coronary sinus os, when present, and the right-sided atrioventricular valve, when present). In patients with tricuspid atresia, the cryoablation lesion is placed from the coronary sinus os to the inferior vena cava os. The absence of a tricuspid anulus and the close proximity to the underlying atrioventricular node and coronary artery mitigate against placement of additional lesions in this area. ${ }^{26,27}$ The issue of isthmus block becomes more difficult when considering other single ventricle diagnoses. In general, cryoablation lesions can be placed to connect the coronary sinus os with the associated atrioventricular valve to achieve isthmus block and avoid complete heart block. Patients with single ventricle who have a defined right atrium, coronary sinus, and right ventricle have the same predictive location of the atrioventricular node in the triangle of Koch as do patients with normal anatomy. ${ }^{28}$ The relationship of the coronary sinus to the atrioventricular node in patients with double-inlet left ventricle, unbalanced atrioventricular canal, and other complex forms of single ventricle are less predictive and cannot be relied on to identify the atrioventricular node, ${ }^{29}$ nor can the distance between the coronary sinus and the anulus in these patients be interpreted as the isthmus, even though in our practice we have treated it as 
such. Oftentimes the distance between the coronary sinus and the atrioventricular valve is long and quite distinct from the normal anatomy on which extensive studies are based. ${ }^{30}$ More detailed electrophysiologic mapping in these complex forms of single ventricle will be necessary to determine whether the area between the coronary sinus os and the atrioventricular valve participates in atrial reentry tachycardia.

\section{Arrhythmia Recurrence}

For the entire series, arrhythmia recurrence is $12.5 \%$, with only $10 \%$ of patients receiving long-term antiarrhythmic medications; these patients were among the first 8 patients in our series. Since applying the more extensive modified rightsided maze procedure for atrial reentry tachycardia, we have had no recurrence of atrial tachycardia in subsequent patients. Similarly, isthmus cryoablation was ineffective for atrial fibrillation, which has been eliminated with the use of the maze-Cox III procedure. The maze-Cox III procedure represents a combination of the right-sided maze procedure, appropriate for anatomic substrate (Figures 2-4), combined with the left-sided series of incisions and cryoablation lesions as described by Cox and associates ${ }^{31}$ (Figure 5). Some authors ${ }^{32,33}$ have used intraoperative radiofrequency ablation and microwave energy, which are associated with higher recurrence rates. Others report that a right-sided procedure will effectively treat patients who have congenital heart disease with accompanying atrial fibrillation ${ }^{20,25}$; longterm data are not available in that population. Similar to our experience, other studies show recurrence of atrial fibrillation with lesions limited to the right atrium. ${ }^{24,34}$ Recurrent atrial fibrillation in our single ventricle population causes unfavorable hemodynamic consequences, which are less well tolerated than in the two ventricle population. Because of this, we prefer to perform the maze-Cox procedure, which is associated with the lowest recurrence rate.

\section{Relative Morbidity}

Most of the morbidity in our series occurred in the atrial fibrillation group, which had the maze-Cox III procedure. These patients were older at Fontan conversion $(P<.01)$, had atrial arrhythmias for a longer time $(P<.02)$, had a longer aortic crossclamp time $(P<.003)$, and had a higher incidence of perioperative renal insufficiency $(P<.0001)$ than did the isthmus cryoablation and modified right-sided maze groups. These data show important trends, which should stimulate earlier referral, before the onset of atrial fibrillation at a time when the less invasive and more expedient modified right-sided maze procedure can be performed. Other beneficial effects of early operation include prevention of progressive myocardial dysfunction caused by atrial arrhythmias, cessation of potentially toxic antiarrhythmic agents, and improved functional class that is associated with Fontan conversion and arrhythmia surgery.

\section{Exercise Tolerance}

It is interesting to speculate on the predominant causative factor for improved exercise tolerance: the anatomic repair, arrhythmia ablation, antiarrhythmic agent cessation, or selfdirected physical conditioning through exercise. All of these therapeutic modalities have been associated with increased functional class and/or improved ventricular function. ${ }^{35,36}$ The principal indication for operation in our cohort of 12 patients who underwent preoperative and postoperative exercise testing was atrial reentry tachycardia in 7 patients, pathway obstructions in 4, and circular venous circulation in 1 . Because of the small number of cases, and because multiple therapeutic interventions were performed simultaneously, it would appear that the relative hierarchical therapeutic importance of any single intervention would require a carefully controlled study with large numbers of subjects.

Fontan conversion with arrhythmia surgery is a safe and efficacious operation. Patient selection and adherence to standard reoperative techniques should optimize outcome. Debilitating arrhythmias are cured, and patients have an improvement in functional class and perform significantly better during exercise testing. We recommend that patients with atriopulmonary Fontan connections be closely monitored for the development of obstructive pathways, valvular dysfunction, and atrial arrhythmias. Fontan conversion should be seriously considered under these circumstances, even if the only indication is debilitating atrial arrhythmias. Surgical intervention before the development of atrial fibrillation results in less surgical morbidity. Cardiac transplantation may be required in the short- or long-term in some of these patients; however, in our experience, the long-term outcome of patients with identifiable causes of ventricular dysfunction treated with Fontan conversion is superior to the outcome of those referred for cardiac transplantation.

\section{References}

1. Driscoll DJ, Offord KP, Feldt RH, Schaff HV, Puga FJ, Danielson GK. Five- to fifteen-year follow-up after Fontan operation. Circulation. 1992;85:469-96.

2. Gewillig M, Wyse RK, de Leval MR, Deanfield JE. Early and late arrhythmias after the Fontan operation: predisposing factors and clinical consequences. Br Heart J. 1992;67:72-9.

3. Cromme-Dijkhuis AH, Hess J, Hählen K, Henkens CMA, BinkBoelkens EME, Eygelaar AA, et al. Specific sequelae after Fontan operation at mid- and long-term follow-up. J Thorac Cardiovasc Surg. 1993;106:1126-32.

4. Mertens L, Hagler DJ, Sauer U, Somerville J, Gewillig M. Proteinlosing enteropathy after the Fontan operation: an international multicenter study. J Thorac Cardiovasc Surg. 1998;115:1063-73.

5. Balaji S, Gewillig M, Bull C, de Leval MR, Deanfield JE. Arrhythmias after the Fontan operation. Circulation. 1991;84 (Suppl):III-162-7.

6. Pearl JM, Laks H, Stein DG, Drinkwater DC, George BL, Williams RG. Total cavopulmonary anastomosis versus conventional modified Fontan procedure. Ann Thorac Surg. 1991;52:189-96.

7. Marcelletti CF, Hanley FL, Mavroudis C, McElhinney DB, Abella RF, Marianeschi SM, et al. Revision of previous Fontan connections to 
total extracardiac cavopulmonary anastomosis: a multi-center experience. J Thorac Cardiovasc Surg. 2000;119:340-6.

8. Mavroudis C, Zales VR, Backer CL, Muster AJ, Latson LA. Fenestrated Fontan with delayed catheter closure: effects of volume loading and baffle fenestration on cardiac index and oxygen delivery. Circulation. 1992;86(Suppl):II-85-92.

9. Stamm C, Friehs I, Mayer JE, Zurakowski D, Triedman JK, Moran AM, et al. Long-term results of the lateral tunnel Fontan operation. $J$ Thorac Cardiovasc Surg. 2001;121:28-41.

10. de Leval MR, Kilner P, Gewillig M, Bull C. Total cavopulmonary connection: a logical alternative to atriopulmonary connection for complex Fontan operations-experimental studies and early clinical experience. J Thorac Cardiovasc Surg. 1988;96:682-95.

11. de Leval MR, Dubini G, Migliavacca F, Jalali H, Camporini G, Redington A, et al. Use of computational fluid dynamics in the design of surgical procedures: application to the study of competitive flows in cavopulmonary connections. J Thorac Cardiovasc Surg. 1996; 111:502-13.

12. Gandhi SK, Bromberg BI, Rodefeld MD, Schuessler RB, Boineau JP, Cox $\mathrm{JL}$, et al. Lateral tunnel suture line variation reduces atrial flutter after the modified Fontan operation. Ann Thorac Surg. 1996;61:1299-309.

13. Mavroudis C, Backer CL, Deal BJ, Johnsrude CL. Fontan conversion to cavopulmonary connection and arrhythmia circuit cryoablation. $J$ Thorac Cardiovasc Surg. 1998;115:547-56.

14. Deal B, Mavroudis C, Backer CL, Johnsrude CL, Rocchini AP. Impact of arrhythmia circuit cryoablation during Fontan conversion for refractory atrial tachycardia. Am J Cardiol. 1999;83:563-8.

15. Deal BJ, Mavroudis C, Johnsrude CL, Buck SH, Backer CL. Comparison of anatomic isthmic block with modified right atrial maze procedure for late atrial tachycardia in Fontan patients. Circulation. In press.

16. Kao JM, Alejos JC, Grant PW, Williams RG, Shannon KM, Laks H. Conversion of atriopulmonary to cavopulmonary anastomosis in management of late arrhythmias and atrial thrombosis. Ann Thorac Surg. 1994;58:1510-4.

17. McElhinney DB, Reddy VM, Moore P, Hanley FL. Revision of previous Fontan connections to extracardiac or intraatrial conduit cavopulmonary anastomosis. Ann Thorac Surg. 1996;62:1276-82.

18. Kreutzer J, Keane JF, Lock JE, Walsh EP, Jonas RA, Castaneda AR, et al. Conversion of modified Fontan procedure to lateral atrial tunnel cavopulmonary anastomosis. J Thorac Cardiovasc Surg. 1996; 111:1169-76

19. Vitullo DA, DeLeon SY, Berry TE, Bonilla JJ, Chhangani SV, Cetta F, et al. Clinical improvement after revision in Fontan patients. Ann Thorac Surg. 1996;61:1797-804.

20. Scholl FG, Alejos JC, Laks H. Revision of the traditional atriopulmonary Fontan connection. Adv Card Surg. 1997;9:217-27.

21. van Son JA, Mohr FW, Hambsch J, Schneider P, Hess H, Haas GS. Conversion of atriopulmonary to lateral atrial tunnel cavopulmonary anastomosis to extracardiac conduit Fontan modification. Eur $J$ Cardiothorac Surg. 1999;15:150-8.

22. Mavroudis C, Deal BJ, Backer CL, Johnsrude CL. The favorable impact of arrhythmia surgery on total cavopulmonary artery Fontan conversion. Pediatr Card Surg Annu Sem Thorac Cardiovasc Surg. 1999;2:143-56

23. Mavroudis C, Backer CL, Kohr LM, Deal BJ, Stinios J, Muster AJ, et al. Bidirectional Glenn shunt in association with congenital heart repairs: the 11/2 ventricular repair. Ann Thorac Surg. 1999;68:976-82.

24. Ghai A, Harris L, Harrison DA, Webb GD, Siu SC. Outcomes of late atrial tachyarrhythmias in adults after the Fontan operation. $\mathrm{J} \mathrm{Am} \mathrm{Coll}$ Cardiol. 2001;37:585-92.

25. Theodoro DA, Danielson GK, Porter CJ, Warnes CA. Right-sided maze procedure for right atrial arrhythmias in congenital heart disease. Ann Thorac Surg. 1998;65:149-53.

26. Thoele DG, Ursell PC, Ho SY, Smith A, Bowman FO, Gersony WM, Anderson RH. Atrial morphologic features in tricuspid atresia. $J$ Thorac Cardiovasc Surg. 1991;102:606-10.

27. Orie JD, Anderson C, Ettedgui JA, Zuberbuhler JR, Anderson RH. Echocardiographic-morphologic correlations in tricuspid atresia. J Am Coll Cardiol. 1995;26:750-8.

28. Wilcox BR, Anderson RH. Surgical anatomy of the heart. Wilcox BR, Anderson RH, editors. New York: Raven Press; 1985.
29. Ho SY, Gerlis LM, Toms J, Lincoln C, Anderson RH. Morphology of the posterior junctional area in atrioventricular septal defects. Ann Thorac Surg. 1992;54:264-70.

30. Feld GK, Fleck RP, Chen PS, Boyce K, Bahnson TD, Stein JB, et al. Radiofrequency catheter ablation for the treatment of human type 1 atrial flutter: identification of a critical zone in the reentrant circuit by endocardial mapping techniques. Circulation. 1992;86;1233-40.

31. Cox JL, Boineau JP, Schuessler RB, Jaquiss RDB, Lappas DG. Modification of the maze procedure for atrial flutter and atrial fibrillation. J Thorac Cardiovasc Surg. 1995;110;4473-84.

32. Benussi S, Pappone C, Nascimbene S, Oreto G, Valdera A, Stefano $\mathrm{PL}$, et al. A simple way to treat chronic atrial fibrillation during mitral valve surgery: the epicardial radiofrequency approach. Eur $J$ Cardiothorac Surg. 2000;17:524-9.

33. Spitzer SG, Richter P, Knaut M, Schuler S. Treatment of atrial fibrillation in open-heart surgery - the potential role of microwave energy. Thorac Cardiovasc Surg. 1999;47:374-8.

34. Betts TR, Roberts PR, Allen SA, Salmon AP, Keeton BR, Haw MP, et al. Electrophysiological mapping and ablation of intra-atrial reentry tachycardia after Fontan surgery with the use of noncontact mapping system. Circulation. 2000;102:419-25.

35. Tomassoni TL, Galioto FM Jr, Vaccaro P, Vaccaro J. Effect of exercise training on exercise tolerance and cardiac output in children after repair of congenital heart disease. Sports Training Med Rehab. 1990; 2:57-62.

36. McLaran CJ, Gersh BJ, Sugrue DD, Hammill SC, Seward JB, Holmes DR Jr. Tachycardia induced myocardial dysfunction: A reversible phenomenon? Br Heart J. 1985:53:323-7.

\section{Discussion}

Dr Scott M. Bradley (Charleston, SC). Since its introduction in the mid-1990s, Fontan conversion has resulted in significant hemodynamic improvement in patients with failing Fontan operations. Unfortunately, it has also become apparent that isolated Fontan conversion provides inconsistent control of atrial arrhythmias, despite the fact that it may include removal of a portion of the atrium and elimination of high pressure within the atrium. Dr Mavroudis and his group have pioneered the concept of adding antiarrhythmia surgery to Fontan conversion. Their approach has included both the placement of specific intra-atrial lesions and the placement of a permanent transmural pacemaking lead for antitachycardia and bradycardia pacing therapies. This report documents their evolution to a standardized right-sided approach for atrial reentry tachycardia and a combined right- and left-sided approach (maze III) for atrial fibrillation. At a mean follow-up of $2 \frac{1}{2}$ years, there has been excellent control of atrial arrhythmias, which is a clear improvement over Fontan conversion alone.

The overall surgical results in these 40 patients were outstanding. This is particularly notable because each of these is a lengthy, repeat operation in a patient with palliated cardiovascular physiology.

I have several questions. The first concerns your current use of mapping. Since you have evolved to a fairly standardized operative approach, do you still find preoperative and, in particular, intraoperative mapping to be of use? If so, how does it currently modify your operative approach?

Second, 2 of your patients, who had no preoperative arrhythmias, underwent prophylactic arrhythmia surgery at the time of Fontan conversion. Do you recommend this prophylactic approach in all such patients undergoing Fontan conversion? If so, which arrhythmia operation should be done: right-sided alone or combined right- and left-sided?

Finally, could you expand on who should not have this operation? Obviously the choice between heart transplantation and 
Fontan conversion can be a difficult one in specific patients. Ventricular function provides some guidance in making this decision. Have you developed any other more specific criteria for deciding who should not undergo a Fontan conversion?

In the future we look forward to further reports on your patients and, in particular, their rhythm status with longer-term follow up. I congratulate you for your innovative approach and for leading our field in this endeavor.

Dr Mavroudis. We performed conscientious mapping in all patients, certainly early on; otherwise we never would have come to the conclusion that the isthmus block was not effective therapy and that we had to proceed to a more standardized operation. Therefore, this has helped us. However, at present we do not need to do intraoperative electrophysiologic mapping because the operation has been standardized to 2 types: right-sided maze for atrial reentry tachycardia and maze-Cox III for atrial fibrillation. We continue to do it so that we might find some other parts of the reentrant circuits that might be helpful to us in the future. For those who are attempting to do this operation, I think a preoperative electrophysiologic study in the catheterization laboratory is sufficient; it would not have to be done in the operating room.

We performed prophylactic ablations in 2 patients for a number of reasons. Extracardiac connections limit intracardiac access for subsequent arrhythmia therapy whether it is for catheter ablation or pacemaker implantation. The added time to perform prophylactic ablation did not present a major impediment, and we thought it prudent to anticipate the possibility of future arrhythmias with a possible solution. I think it was just an educated guess at that point whether they would need it or not.

That this type of arrhythmia surgery should be done in all patients undergoing a primary Fontan operation is an issue for further study. Edward Bove's group has performed prophylactic incisions, not cryoablations, and found that no protective effect as to new arrhythmias was realized. We are embarking on a study now to try to answer that question, although a large number of patients will be needed.

The question of whether to perform cardiac transplantation or Fontan revision is an interesting one. Our present policy and posture, such as it is, is that if we find a substrate that can be repaired, such as a valve lesion, an obstructive lesion, or cardiac dysfunction based on arrhythmias, then we would prefer to attempt a Fontan revision. If none of these causative substrates can be found and if function is poor, then we would recommend cardiac transplantation, as we have in 5 patients who are not included in this cohort of patients.
Dr Francis Fontan (Bordeaux, France). Dr Mavroudis, I would like to congratulate you for these superb results and your pioneering work in this difficult field of cardiac surgery. I would like to ask you 3 questions.

No patient in your series had protein-losing enteropathy. Is that because, in your opinion, protein-losing enteropathy is a contraindication to conversion?

You already were asked a question about the 2 patients who had no preoperative atrial arrhythmias. What was the reason for conversion, first, in these 2 patients, and why did you perform arrhythmia surgery since, due to the postoperative unloading of the remnants of the right atrium, late atrial arrhythmias are very unlikely?

Finally, I would like to ask your opinion regarding the long and still debated question of fenestration, which personally I do not favor.

Dr Mavroudis. It is a great honor for me to answer a question from you, Professor Fontan, who started this whole pathway, and I thank you for your questions.

We did not really exclude patients with protein-losing enteropathy. They simply were the types of patients who were not referred because of the severity of their disease. I believe that we deferred to operate on 2 such patients because of poor ventricular function. We did, however, operate on our 41st patient recently, last month, who had had protein-losing enteropathy. I did not include that patient in this series mainly because we really do not know his results and will not know them for another 4 or 5 months. He is doing well, but the outcome of the operation on the state of his protein-losing enteropathy is uncertain. Categorically, we would not exclude a patient with protein-losing enteropathy with the experience we have had so far, but I think we would have to ascribe a higher mortality for that particular patient.

A number of groups have tried unloading the right atrium in light of repairing pathway obstructions, thinking that would be enough to cure the atrial arrhythmia. None of these attempts has been successful so far as I can see. We believe that any time a Fontan conversion is attempted, it should be accompanied by an appropriate arrhythmia operation, as noted in this presentation.

Fenestration, of course, continues to be a controversy. In those patients with protein-losing enteropathy, fenestration will certainly increase cardiac output. Jack Rychik and Tom Spray from Philadelphia have promoted the idea that decreased cardiac output is a causative factor for protein-losing enteropathy. Under these circumstances, increasing cardiac output by fenestration may help to ameliorate the problem. We use fenestration selectively, but not in this particular group of patients unless they have protein-losing enteropathy. 